\title{
A Formação de professores para inclusão tratada na Revista Brasileira de Educação Especial: uma análise
}

\author{
Jacqueline Lidiane de Souza Prais* \\ Vanderley Flor da Rosa**
}

\section{Resumo}

A formação de professores para atuar juntos aos alunos com necessidades educacionais especiais (NEE) tem sido apontada pela literatura na área de Educação Especial e da Educação como uma necessidade emergente para se efetivar a educaçáo inclusiva. Motivados por esse argumento, este artigo tem o objetivo de caracterizar as publicaçôes referentes ao tema formação de professores para inclusão dos alunos com NEE contidas na Revista Brasileira de Educação Especial no período de 2005 a 2014. Utiliza-se como metodologia de pesquisa a revisão sistemática das ediçóes online disponíveis. Os primeiros resultados indicaram 333 artigos publicados contemplando diversos temas na área da Educação Especial, dentre estes 19 foram selecionados para análise do conteúdo, considerando que tinham como tema central a formação de professores. Após a leitura dos artigos e análises, foram organizados em cinco categorias que apresentaram as seguintes discussôes: análise da/na formação inicial de professores; a formação de professores como prática colaborativa para inclusão; análise de curso/programa de formação continuada; revisôes e análises de produçôes científicas acerca da formação de professores e; por fim, a necessidade de formação pedagógica para atuação educacional. Dentre os resultados obtidos nesta pesquisa, evidenciou-se que além do tema formaçáo de professores ter assumido papel de relevância nas pesquisas, ocupa pouco espaço como objeto central das pesquisas e, assim, se faz necessário ampliar as análises para contribuir com a divulgação de trabalhos desenvolvidos na formação inicial e continuada, bem como para reformulação/reestruturação de cursos e programas.

Palavras-chave: Formação de professores; Educação Especial; Revisão sistemática; Análise.

\footnotetext{
* Mestra em Ensino de Ciências Humanas, Sociais e da Natureza pela Universidade Tecnológica Federal do Paraná, Londrina, Paraná, Brasil.

** Professor doutor da Universidade Tecnológica Federal do Paraná, Cornélio Procópio, Paraná, Brasil.
} 


\section{The teachers training for the inclusion treated in the Brazilian Journal of Special Education: an analysis}

\section{Abstract}

The teachers training to act with the students with special educational needs (NEE) (acronym in Portuguese for Special Educational Needs) has been pointed out by the literature in the area of Special Education and the Education as an emerging need to implement the inclusive education. Being motivated by this argument, this article aims at characterizing the publications which refer to the teachers training theme for the inclusion of the students with NEE contained in the Brazilian Journal of Special Education from 2005 to 2014 . As the research methodology, it was used the systematic review of the available online editions. The first results indicated 333 published articles contemplating many themes in the area of Special Education, among them, 19 were selected for the content analysis, considering that they had as central theme the teachers training. After the reading of the articles and analysis, it was organized in five categories which present the following conclusions: analysis of the/in the initial teachers training; the teachers training as a collaborative practice for the inclusion; analysis of continued formation course/program; reviews and analysis of the scientific productions about the teachers training and; finally, the necessity of pedagogic formation for the educational action. Among the obtained results in this research, it was reported that beyond the teachers training theme has assumed a relevant role in the researches, it takes little space as central object in the researches and, thus, it is necessary to extend the analysis to contribute to the dissemination of the developed papers in the initial and continued formation, as well as to the courses and programs reformulation/restructuring.

Keywords: Teachers training; Special Education; Systematic review; Analysis.

\section{Introdução}

As análises sistemáticas de produçôes científicas tem sido uma preocupação para pesquisadores em qualquer área do conhecimento. Essas pesquisas identificam e sistematizam estudos já realizados na área, bem como evidenciam os encaminhamentos metodológicos e fundamentos teóricos para compreensão do contexto e da realidade (SAMPAIO; MANCINI, 2007). Nessa mesma direção, este artigo visa contribuir para novos estudos e discussôes imprescindíveis diante do tema formação de professores para a inclusão de alunos com necessidades educacionais especiais (NEE).

Sabe-se que, a partir da década de 1990 no Brasil, a inclusão toma destaque primordialmente com a publicação Declaração Mundial sobre Educação para Todos: satisfação das necessidades básicas de aprendizagem, conhecida como Declaração de Jomtien (BRASIL, 1990). Esse documento representa um marco para Educação Especial, senão o mais importante, que desencadeou a adequaçóes dos países para a inclusão das pessoas com deficiência. 
A Declaração, no artigo 3, prevê que é necessário "tomar medidas que garantam a igualdade de acesso à educação aos portadores de todo e qualquer tipo de deficiência, como parte integrante do sistema educativo" (BRASIL,1990). Ainda, há nessa declaração o realce em buscar a garantia do acesso e a permanência de todos na Educação Básica.

A Declaração de Salamanca (BRASIL, 1994) avança nas discussóes sobre Educação Especial firmando o compromisso dos governos para viabilizar a inclusão educacional. É um documento internacional que diz respeito, exclusivamente, a Educação Especial em que reafirma o compromisso de todos com a educação. Destaca-se o termo NEE como "necessidades educacionais especiais refere-se a todas aquelas crianças ou jovens cujas necessidades educacionais especiais se originam em função de deficiência ou dificuldade de aprendizagem" (BRASIL, 1994).

Defende-se na Declaração de Salamanca que é nas escolas regulares, com uma proposta inclusiva, que se constituem meios eficazes de combater atitudes discriminatórias, construindo uma sociedade inclusiva e alcançando educação para todos. Mesmo sendo citado em outros documentos, fica visível que é a partir da Declaração de Salamanca que se ampliou o conceito de educação especial inclusiva.

No entanto, os indicativos legais mostram um contexto histórico que reflete rastros contraditórios entre a inclusão e integração dos alunos com NEE nas escolas. Conceitua-se que a inclusão escolar se apresenta como uma prática não discriminatória da diversidade, mas de respeito e reconhecimento das múltiplas formas de aprender e de abordar as diferentes situaçóes que levam a exclusão social e educativa de muitos alunos (SÁNCHES, 2005).

Em linhas gerais, a formação de professores é um dos pontos críticos que podem influenciar na qualitativa efetivação das políticas inclusivas e consolidação de inclusão escolar. Tal aspecto tem sido objeto de estudo (GLAT; PLETSCH, 2010, VITALIANO, 2010, SOARES, 2010) enfatizando a urgente necessidade de formação pedagógica dos professores pensada de modo que contribua para o ensino mais comprometido ético e politicamente com as exigências do contexto atual.

Do mesmo modo, a inclusão escolar de alunos com NEE não se equivale apenas à inserção de crianças em salas de aulas em função das determinaçóes legais, mas pressupóe um professor preparado e capacitado para receber os alunos. E que, na mesma medida, o docente usufrua de condiçóes necessárias para o ensino, desenvolvimento e aprendizagem dos alunos.

Considerando os aspectos mencionados acima, essa revisão sistemática compreende e discute a contribuição das produçóes científicas para a formação de professores em relação à área de educação especial e educação inclusiva, tendo como base os artigos encontrados na Revista Brasileira de Educação Especial. Parte do problema: de que maneira a formação de professores tem sido contemplada nas publicaçôes da Revista Brasileira de Educação Especial? Enfim, o objetivo principal é o de caracterizar o tema formação de professores na Revista Brasileira de Educação Especial. 


\section{Método}

Esta revisão sistemática foi realizada no periódico denominado Revista Brasileira de Educação Especial nas publicações disponíveis online entre os anos 2005 a 2014, que tiveram como foco de pesquisa a formação de professores a partir de três etapas principais: busca por descritores nas publicações do periódico, seleção por relevância do tema e análise de conteúdo.

Após o levantamento das produçóes em acesso online, realizou-se uma busca sistematizada com critérios específicos no periódico a partir de palavras consideradas no tema. Na segunda etapa, realizou-se uma seleção por meio dos resumos destes estudos que contemplavam os principais critérios estabelecidos. E, por fim, selecionadas pesquisas por relevância frente à temática foi estudado cada artigo por meio da análise de conteúdo.

Vale destacar que a escolha do periódico partiu de alguns critérios, os quais são: ser avaliado e classificado com Qualis A2 pela CAPES; ter produçôes disponíveis online e ser de interesse pessoal dos pesquisadores em realizar leituras sobre os temas formação de professores de Educação Especial, educação e inclusão escolar. Espera-se que tal levantamento bibliográfico ofereça contribuiçôes teórico-metodológicas para posteriores discussóes e estudos frente ao tema para inclusão escolar.

\section{Procedimento}

O primeiro procedimento utilizado para coleta de dados consistiu de uma busca pelo site do periódico para acessar as ediçóes disponíveis nesta ferramenta. A partir dessa ferramenta de busca, obteve-se acesso às 333 produçôes publicadas nos últimos 10 anos (2005 a 2014) nas ediçóes dos volumes de 11 a 20 do periódico, sendo que, na data de acesso (29/12/2014), a última publicação trimestral do ano de 2014 ainda não havia sido divulgada. Em seguida, optou-se por salvar em pastas as produçóes de cada edição para realizar uma busca sistematizada com critérios específicos no periódico.

Para padronização e organização da busca foram utilizadas as seguintes palavras: Formação de professores; Formação do professor; Formação Docente; Formação Inicial, Formaçáo Continuada; Capacitação, Treinamento e Programa de formação que estivessem relacionados ao professor. Tais termos foram usados para uma análise e seleção pelos resumos e das palavras-chaves de todos os trabalhos encontrados, excluindo-se aqueles que não sugeriram vinculação entre as expressōes destacadas de nosso foco de pesquisa. Visto que, "nem todo o material de análise é susceptível de dar lugar a uma amostragem, e, nesse caso, mais vale abstermo-nos e reduzir o próprio universo" (BARDIN, 2009, p.123). O critério utilizado para seleção dos textos a serem analisados foi o artigo conter a formaçáo do professor como tema central.

Para discussão e reflexôes sobre as pesquisas selecionadas norteou-se pela análise de conteúdo com base em Bardin (2009) definida como uma técnica de tratamento de dados de pesquisa, voltada para uma análise objetiva, sistemática e quantitativa do conteúdo de "comunicaçôes", que no caso desta pesquisa se refere às produçôes 
científicas de um periódico. A análise dos artigos possibilitou a organização de cinco categorias.

\section{Resultados e discussões}

Apresentam-se inicialmente os dados quantitativos obtidos nas etapas da coleta de dados para assim estabelecer descriçóes e reflexôes sobre estes números que se mostram relevantes para a pesquisa e o pesquisador. Por fim, tece a descrição dos estudos selecionados para análise apontando os aspectos referentes à formação de professores.

A pesquisa foi realizada tendo como parâmetro a concentração de descritores relacionados à formação de professores nos resumos e palavras-chave, descritores. Sobre as palavras consideradas na pesquisa foram encontrados 104 mençóes em um total de 66 produçōes científicas. Ou seja, 19,82\% das publicaçôes da Revista Brasileira de Educação Especial entre 2005 a 2014 citaram a formação do professor e 80,18\% (267) das pesquisas que não se remeteram a este tema, sendo descartados.

Foram mencionados 25 vezes o descritor Formação de professores, Formação do professor 10 vezes, Formação do Docente 5 vezes. Na busca pela expressão Formação Inicial foram citados 6 vezes, Formação Continuada 11 vezes, capacitação 11 vezes, treinamento 1 e, 35 vezes foram mencionadas palavras relacionadas a programa de formação. Cabe indicar que as três últimas palavras pesquisadas foram destacadas naquelas publicaçóes que atrelavam a formação do professor sendo que foram encontradas palavras como: cursos de licenciaturas, programa de formação pedagógica, preparação pedagógica, formaçáo em serviço, programa de qualificação profissional inicial, entre outras.

Tabela 1 - Distribuição das palavras consideradas na seleção das produçóes científicas

\begin{tabular}{|c|c|c|c|c|c|c|c|c|c|c|c|}
\hline $\begin{array}{c}\text { Palavras } \\
\text { Pesquisadas }\end{array}$ & $\mathbf{2 0 0 5}$ & $\mathbf{2 0 0 6}$ & $\mathbf{2 0 0 7}$ & $\mathbf{2 0 0 8}$ & $\mathbf{2 0 0 9}$ & $\mathbf{2 0 1 0}$ & $\mathbf{2 0 1 1}$ & $\mathbf{2 0 1 2}$ & $\mathbf{2 0 1 3}$ & $\mathbf{2 0 1 4}$ & Total \\
\hline $\begin{array}{c}\text { Formaçáo de } \\
\text { Professores }\end{array}$ & 2 & 2 & 3 & 1 & 1 & 2 & 4 & 2 & 4 & 4 & 25 \\
\hline $\begin{array}{c}\text { Formação do } \\
\text { Professor }\end{array}$ & 1 & 1 & 1 & 0 & 1 & 2 & 2 & 1 & 0 & 1 & 10 \\
\hline $\begin{array}{c}\text { Formaçáo } \\
\text { Docente }\end{array}$ & 0 & 0 & 0 & 1 & 1 & 0 & 1 & 0 & 1 & 1 & 5 \\
\hline $\begin{array}{c}\text { Formação } \\
\text { Inicial }\end{array}$ & 0 & 0 & 0 & 1 & 1 & 1 & 2 & 0 & 0 & 1 & 6 \\
\hline $\begin{array}{c}\text { Formaçáo } \\
\text { Continuada }\end{array}$ & 0 & 1 & 2 & 1 & 1 & 1 & 2 & 2 & 0 & 1 & 11 \\
\hline Capacitaçáo & 2 & 1 & 0 & 1 & 1 & 1 & 0 & 1 & 2 & 2 & 11 \\
\hline Treinamento & 0 & 0 & 0 & 0 & 0 & 0 & 0 & 1 & 0 & 0 & 1 \\
\hline
\end{tabular}


Continuação da Tabela 1

\begin{tabular}{|c|c|c|c|c|c|c|c|c|c|c|c|}
\hline $\begin{array}{c}\text { Programa de } \\
\text { Formaçã́o e } \\
\text { Outros }\end{array}$ & 0 & 1 & 1 & 5 & 2 & 2 & 5 & 6 & 4 & 9 & 35 \\
\hline Total & 5 & 6 & 7 & 10 & 8 & 9 & 16 & 13 & 11 & 19 & 104 \\
\hline
\end{tabular}

Fonte: Dados obtidos na seleção das publicaçōes de 2005 a 2014

A partir da Tabela 1, evidencia-se que no ano de 2014 encontramos um maior número de menções, 19, das palavras consideradas na seleção e que em 2005, com 5 mençôes, o ano com menor citação das palavras destacadas. No entanto, conforme indicado no Gráfico 1 abaixo, o maior número de produçóes científicas pré-selecionadas por este critério foram 12 publicaçóes relacionadas ao tema em 2014, e 4 em 2006 e em 2009.

Gráfico 1 - Número de produçôes científicas selecionadas por ano a partir das palavras consideradas

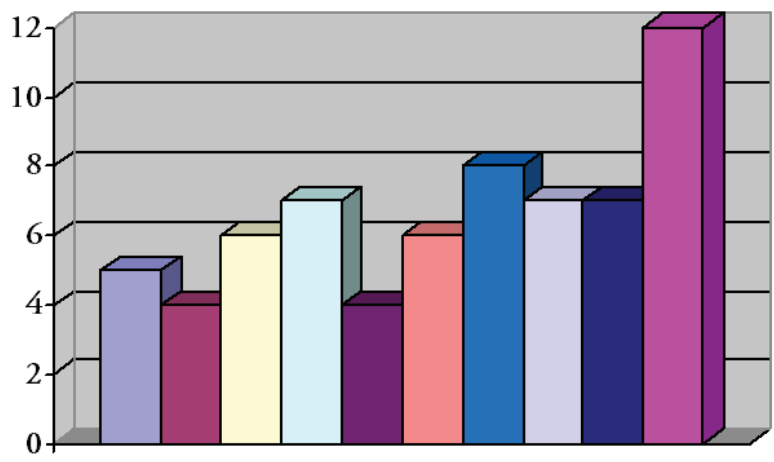

Seleçáo de produçóes científicas por ano

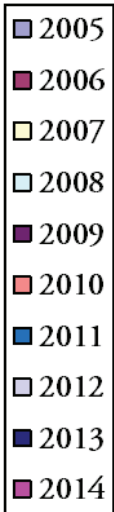

Dentre os 66 estudos selecionados o maior de número de trabalhos foram a partir de relatos de pesquisas (43), seguido por resenhas (10), revisão de literatura (7) - nos quais computamos também revisóes realizadas em eventos - e, por último, ensaios (6).

$\mathrm{Na}$ segunda etapa, realizou-se uma seleção por relevância do tema formação de professores nos estudos pré-selecionados a partir de critérios estabelecidos, pois se identifica que as palavras consideradas na seleção estavam sendo usadas nas pesquisas de forma sucinta ou emergiu de outra discussáo dentro do estudo. Nesse sentido, priorizaram-se as pesquisas que contemplaram a formação docente na área de Educação Especial como objeto central de estudo.

Diante este critério de seleção por relevância, foram descartados primeiramente os 10 estudos apresentados em forma de resenhas que apenas mencionavam o tema 
formação sem o aprofundamento da discussão por se caracterizar em análise das obras e não do tema.

A análise das pesquisas seguiu por uma leitura flutuante dos relatos de pesquisa, revisōes de literatura e ensaios para verificar se o tema em caracterização no periódico foi apresentado como eixo principal na pesquisa ou como aspecto secundário, introdutório ou conclusivo. Dessa leitura evidenciou-se que a formação de professores não foi foco principal de 37 pesquisas, sendo ela apresentada como parte de seu tema principal ou como elemento secundário (introdutório ou conclusivo) emergente da discussão proposta.

Tabela 2 - Seleção por critério de relevância do tema "formação de professores" nas pesquisas selecionadas

\begin{tabular}{|c|c|c|c|}
\hline Tipo de Pesquisa & Pré-selecionadas & Selecionadas & Descartadas \\
\hline Relatos de Pesquisa & 43 & 13 & 30 \\
\hline Resenhas & 10 & 0 & 10 \\
\hline $\begin{array}{c}\text { Revisóes de } \\
\text { Literatura }\end{array}$ & 7 & 3 & 4 \\
\hline Ensaios & 6 & 3 & 3 \\
\hline Total & 66 & 19 & 47 \\
\hline
\end{tabular}

Fonte: Elaboração própria a partir dos dados analisados com a seleção por relevância do tema

A partir da seleção por critério de relevância do tema "formação de professores" nas pesquisas selecionadas deparou-se com 19 pesquisas (29\%) que o contemplavam como eixo central de estudo. No entanto, 47 pesquisas (71\%) abordavam ou citavam o tema formaçáo de professores como aspecto secundário: ora como aspecto introdutório ou conclusivo de outro tema principal de pesquisa e, por isso, foram descartadas para análise de conteúdo.

Diante esses primeiros dados, percebe-se que a formação docente na área da Educação Especial tem sido mencionada nas publicações da Revista Brasileira de Educação Especial. Porém estas citaçóes são suscitadas pela abrangência de outros temas e não como foco de estudo das publicaçôes. Ao retomar o universo de 333 textos publicados entre 2005 a 2014 , apenas $1,75 \%$ tem como ênfase estudar a formação de professores.

Após a busca por descritores nas publicaçóes do periódico e seleção por relevância, finalmente 19 pesquisas foram tomadas para análise do conteúdo, as quais estão sistematizadas em cinco categorias que seguiram as discussôes e implicaçóes dos estudos na formação dos professores para atuar juntos aos alunos com NEE e, principalmente, para as novas contribuiçôes científicas.

A análise da/na formação inicial de professores, a primeira categoria organizada, se compôs de quatro trabalhos selecionados que tinham por objetivo analisar a organização curricular de cursos de formação inicial bem como, apontar reflexôes 
e desafios imperantes neste nível. Sobre formação de professores como prática colaborativa para inclusão, análise de curso/programa de formação continuada e, revisôes sistemáticas e análises de produçôes acerca da formação de professores também organizaram-se com quatro trabalhos cada. E, por fim, a necessidade de formação pedagógica especificada contou com três trabalhos.

\section{Descrição dos estudos}

\section{Análise da/na formação inicial de professores}

Michels (2005) toma como objeto de análise a organização curricular do curso de formação de professores para a educação especial na Universidade Federal de Santa Catarina (UFSC), ofertado nas modalidades regular e emergencial no período de 1998-2001, na qual depreende o predomínio do modelo médico-psicológico e que este constitui-se em uma disposiçẫo incorporada.

Tendo analisado as disciplinas e suas respectivas ementas, Michels (2005) percebe a permanência da compreensão do fenômeno educacional relacionado ao aluno com diagnóstico de deficiência pela base biológica e, de maneira mais acentuada, pela Psicologia. Compreende as marcas das contradiçóes históricas e práticas no contexto social da educaçẫo especial dentro da formação na medida em que se explicitam as contradiçóes e os conflitos que a perpassam.

Fonseca-Janes e Omote (2013) analisam as matrizes curriculares dos cursos de Pedagogia da Universidade Estadual Paulista para a formação em uma perspectiva inclusiva. $\mathrm{Na}$ análise realizada das disciplinas obrigatórias, dos seis cursos de Pedagogia da UNESP cinco possuem disciplinas voltadas para a questáo da Educação Inclusiva, com as mais diversificadas cargas horárias, e quatro possuem disciplinas voltadas para questôes específicas da Educação Especial.

No trabalho de Greguol, Gobbi e Carraro (2013) são discutidos os modelos brasileiro e italiano de formação de professores para atuar na educação especial a partir da análise dos textos legais de ambos os países. Sinalizam que a Itália foi o primeiro país na Europa a promover o fim das escolas especiais e a inclusão de todos os alunos com deficiência nas escolas regulares. Notou-se que neste país as diretrizes governamentais são claras com relação à capacitação de professores para atuar com alunos com necessidades educacionais especiais. Por outro lado, no Brasil, embora tenham ocorrido grandes avanços no que se refere à legislaçáo que sustenta a formação docente, ainda existe uma carência de parâmetros mais específicos sobre os conteúdos mínimos necessários para que os professores tenham maiores subsídios para promover a inclusão com qualidade.

Já, Fiorini e Manzini (2014) identificam as dificuldades encontradas por professores de Educação Física para incluir alunos com deficiência. Por meio de Grupo focal categorizaram os seguintes conteúdos apresentado como dificuldades na prática e formação dos educadores quanto: 1) à Formação; 2) à questão Administrativo-escolar; 3) ao Aluno; 4) ao Diagnóstico; 5) à Família; 6) ao Recurso Pedagógico; 7) à Estratégia de ensino; 8) à Educação Física. Os autores sugerem açôes e conteúdos 
para promover a formação dos professores, sendo uma delas a necessidade de uma formação para professores de Educação Física com foco na inclusão educacional identificando e assumindo as dificuldades encontradas no contexto escolar.

\section{Formação de professores como prática colaborativa para inclusão}

Optou-se por selecionar estes trabalhos em categoria específica, mesmo sabendo que discutem a formação continuada de professores para inclusão e educação especial, porém tal temática tem se mostrado nesta área como tema emergente e prática qualitativa para efetivaçáo da inclusão educacional. Para formação de professores visando à inclusão, a prática pedagógica tem sido entendida como um processo colaborativo entre os profissionais na educação e especialistas a fim de somar conhecimentos e juntos, qualitativamente, promover a educação para todos.

Peterson (2006) discute a filosofia dos programas de inclusão e apresenta detalhes sobre programas de inclusão em um Estado específico dos Estados Unidos, o Estado do Arizona. Nesse contexto, descreve a necessidade de capacitação de professores para a área de educação geral e especial por meio do ensino colaborativo como necessário para aumentar o sucesso da inclusão nos Estados Unidos.

A autora sinaliza que a inclusão é entendida como prática colaborativa e, de que o professor necessita de suportes indispensáveis para inclusão, "além do mais, ambos professores da educação geral e especial precisam adquirir conhecimento sobre pesquisa e práticas eficazes necessárias para ensinar todos alunos com deficiência [...]" (PETERSON, 2006, p.7). Para tanto, afirma que será por meio da formação em serviço do professor sobre métodos e técnicas colaborativas sobre como trabalhar com alunos com deficiência que promoverá aprimoramento das práticas inclusivas.

Toledo e Vitaliano (2012) investigam a eficácia de um programa de formação de professores numa escola de anos finais do Ensino Fundamental, com vistas a favorecer o processo de inclusão de alunos com deficiência intelectual (DI). As autoras utilizam a pesquisa colaborativa a fim de almejar práticas pedagógicas mais inclusivas. Os resultados evidenciaram melhoria da qualidade do processo de inclusão dos alunos com DI e ampliação dos conhecimentos teóricos e práticos acerca da educação inclusiva pelos professores. Comprovou-se, também, que o trabalho colaborativo desenvolvido entre professores do ensino regular e professor especialista em Educação Especial é efetivo para favorecer o processo de inclusão de alunos com DI.

Rosin-Pinola e Del Prette (2014) apresentam uma visáo geral da história e da legislação sobre inclusão bem como as inovaçóes que vêm sendo propostas por educadores e agências governamentais. Identificam, dentre as discussóes, que no contexto das escolas brasileiras e as políticas, "as pesquisas sobre formação em serviço de professores e os materiais publicados pelo MEC têm destacado a necessidade do professor mudar suas práticas, atentando para o aprimoramento da qualidade da relação educativa" (ROSIN-PINOLA; DEL PRETTE, 2014, p.350). Focalizam a formação do professor como necessidade para desenvolver suas habilidades sociais educativas (HSE) para inovar e melhorar interaçóes com todos os alunos. Tal formação se dá por meio da assessoria do especialista junto ao professor para instrumentalizá-lo em HSE 
voltadas para a promoção da inclusão escolar de alunos com NEE. Isto é, uma prática colaborativa entre os profissionais da educação para minimizar os desafios da inclusão frente aos conteúdos e habilidades apreendidos que viabilizam condiçôes de inclusão e efeitos favoráveis à inclusão.

Benitez e Domeniconi (2014) operacionalizaram e avaliaram uma capacitação destinada aos professores da sala de aula regular, da educação especial e pais, de modo a criar condiçôes que vislumbrassem o ensino compartilhado de leitura e escrita para alunos com deficiência intelectual e autismo, incluídos na escola regular. A capacitação contou com a participação da comunidade escolar por meio da orientação sobre a intervenção a ser aplicada em cada contexto de atuação incluindo um tópico sobre as habilidades sociais educativas. As autoras apontam que mesmo que a capacitação seja a primeira ação deste teor, criou condiçôes para desenvolver estratégias inclusivas, de modo a operacionalizar as orientaçôes descritas nos documentos vigentes em relação à inclusão escolar, a partir do envolvimento colaborativo dos integrantes e profissionais da escola.

\section{Análise de curso/programa de formação continuada}

Rodrigues e Capellini (2012) discutem sobre o papel da Educação a Distância na formaçáo continuada de docentes, a partir do levantamento e análise de dados em relaçáo à sua utilizaçáo para formaçáo continuada de professores quanto ao processo de inclusão da pessoa com deficiência. Os resultados indicam que a flexibilidade de horário e o atendimento a grande número de alunos, em diferentes áreas geográficas, destacam-se como pontos positivos desta modalidade, porém, para seu sucesso, é necessária a formação adequada dos formadores/tutores na utilização das novas ferramentas no processo de ensino-aprendizagem.

Vieira e Martins (2013) tomam como objetivo central de pesquisa compreender como um processo de formaçáa pode contribuir para a expressão criativa de profissionais da educação, visando à efetivação da educação inclusiva. Respaldados na Teoria da Subjetividade, elaborada por González Rey, no conceito de criatividade, desenvolvido por Mitjáns Martínez, realizam uma pesquisa-ação, através de um curso de formação. A análise revelou que nem todas as participantes elaboraram estratégias criativas em decorrência da participação no curso, embora duas delas tenham desenvolvido alternativas criativas bastante significativas.

Identificam que os aspectos do curso contribuíram para impulsionar a expressão criativa das participantes, tais como: a possibilidade de participação na elaboração da proposta de formaçáo e o fato de o curso ser realizado em seu lócus de trabalho. Assim, entendem que um processo de formação poderá contribuir para a expressão criativa se considerar e intervir na dimensão pessoal dos participantes, impulsionando o desenvolvimento de elementos subjetivos que a favoreçam, bem como a assunção da condição de sujeito.

Bardy et al (2013) evidenciaram que os Objetos de Aprendizagem (OA) podem favorecer o aprendizado de conteúdos disciplinares, além de serem concebidos como um recurso pedagógico de apoio ao processo de ensino e aprendizagem e, em 
consequência, à inclusão educacional de pessoas com deficiência. Em relação ao processo de formação de professores na modalidade a distância o curso contribuiu para a concretização de uma formação sólida e eficiente dos participantes ao propiciar: a aproximação com o mundo tecnológico; a possibilidade de inserção das tecnologias em sala de aula; a realização de estudos teóricos e práticos; a valorização da diversidade e do potencial de todos os estudantes; inovaçóes nas estratégias e recursos pedagógicos e reflexão na ação.

Já na pesquisa de Bisol e Valentini (2014) apresentam o objeto virtual de aprendizagem Incluir (OA Incluir), construído com o objetivo de criar um instrumento facilitador à formação de professores para a educaçáo na perspectiva da inclusão. Dividido em quatro módulos (Limites, Diversidade, Docência e Surdez), este OA visa ultrapassar a transmissão de informação, propondo uma linha de reflexão que promova e mobilize novas práticas dentro de pressupostos interacionistas/construtivistas.

\section{Revisões sistemáticas e análises de produções acerca da formação de professores}

Marquezine e Tramontina (2006) avaliam as produçóes científicas desenvolvidas pelo corpo discente curso de pós-graduaçáo lato sensu, especialização em Educação Especial-Deficiência Mental na Universidade Estadual de Londrina-Pr, sendo parte do processo para reformulação do currículo do curso de formação continuada de professores.

Os resultados mostraram que as pesquisas foram desenvolvidas em sua maioria, na escola, com alunos especiais, com quantidade equilibrada de pesquisas de levantamento e pesquisas de intervenção, cuja maior incidência de temas foi a de investigaçôes relacionadas a procedimentos de ensino.

Orth, Mangan e Sarmento (2011) realizam um mapeamento de trabalhos realizados no âmbito de dissertaçóes e teses brasileiras que tematizam a formação continuada de professores em Informática na Educaçáo Especial no período de 1990 a 2009. Identificam, a partir das preocupaçóes dos pesquisadores brasileiros nesse período, que há um crescimento pouco significativo em trabalhos na temática. Bem como, há poucas pesquisas problematizando a formação continuada de professores (oito dissertaçóes) e o uso didático pedagógico de recursos informáticos na educação (seis dissertaçôes), considerados pelos autores dois aspectos fundamentais para garantir a inclusão da Diversidade de Necessidades Especiais.

Jesus, Barreto e Gonçalves (2011) se dedicam a fazer um levantamento e analise da produção na área de formaçáo de professor e Educação Especial a partir de trabalhos apresentados no GT15- Educação Especial da Associação Nacional de Pesquisa e Pós-Graduação (ANPEd) no período (2000-2010).

Entre as 14 pesquisas encontradas foram selecionadas a partir de análise do estado da arte na área; formação inicial; formação continuada e avaliação de programas de formação sendo que os apontamentos iniciais indicam que os principais objetos 
de análise são as organizações estruturais dos cursos de formação inicial, com ênfase no curso de Pedagogia.

Ingles et al (2014) analisam bibliograficamente artigos acerca das políticas de educação inclusiva para a formação de professores a partir de uma busca sistematizada no site de periódicos da Coordenaçáo de Aperfeiçoamento de Pessoal de Nível Superior (CAPES). Os descritores encontrados e analisados foram: Políticas de formação docente (cinco artigos); Políticas da formação de professores (três artigos); Políticas de educação inclusiva (um artigo); Educação inclusiva (dois artigos); Formação docente (três artigos) e Legislação educacional (dois artigos).

Indicam a necessidade de disseminação desse tema perante a sociedade, com vistas à importância da atuação docente nessa busca de pressupostos para uma educação inclusiva. Isso confirmou afirmaçóes contundentes de pesquisadores nacionais ao pontuarem que, embora as políticas públicas para essa educação estejam postas, elas ainda não conseguiram atingir as práticas pedagógicas e a formação de professores.

\section{Necessidade de formação pedagógica especificada}

Dentre as pesquisas selecionadas, Vitaliano (2007) investiga a formação do professor universitário para a inclusão de alunos com necessidades educacionais especiais (NEE). A pesquisa apresentou que num universo de 178 professores atuantes em 13 cursos de licenciatura da Universidade Estadual de Londrina, que participaram do estudo, 84\% consideraram que nâo tinham conhecimento suficiente para incluir alunos com NEE. E que 63\% dos participantes se interessaram em participar de um programa de formação para inclusáo de alunos com NEE e indicaram os temas a serem abordados, bem como a metodologia de ensino a ser utilizada.

Ainda, os resultados da análise apontaram a maior clareza na identificação das necessidades percebidas por professores universitários em relaçáo à preparação pedagógica para inclusão de alunos com NEE, bem como a organização de diretrizes para o planejamento de um programa de preparação para suprir essas necessidades.

Faria (2011) apresenta reflexôes sobre o Instrutor de Libras e o Professor de Libras dentro da escola de Educação Básica a partir do Decreto 5.626/2005. Dentre os aspectos sinalizados por Faria (2011) salienta "que é o profissional surdo que tem sido identificado como Instrutor de Libras e tem assumido responsabilidades educacionais inerentes a um professor, fato que deveria ser suprido pelo Professor de Libras" (FARIA, 2011, p.96).

Dessa forma, reconhece à necessária e urgente valorização, formação e profissionalizaçáo do profissional surdo que ensina Libras como um Professor de Libras, sendo um profissional que participa dos debates e tomadas de decisão, e se envolve no processo educativo de seus pares.

Ramalho et al (2014) detectam a carência de formação de professores no tema das Altas Habilidades/Superdotaçáo (AH/SD), particularmente no interior do Brasil. A partir da investigação da conjectura de que há bastante desconhecimento sobre este assunto nas licenciaturas da Universidade Federal de Pelotas (UFPel), o estudo 
de caso indicou que a maioria dos professores não estudam o assunto e este não é abordado no currículo do curso. Com isso, os professores desconhecem a legislação pertinente e nem mesmo sabem que os termos "superdotação" e "altas habilidades" têm o mesmo significado, bem como apresentam diferentes concepçôes mitológicas segundo a literatura de referência, que em sua maioria veem os alunos com AH/SD como um grupo homogêneo e não imagina um superdotado apresentando baixo rendimento escolar.

\section{Considerações finais}

Para compreender a temática que envolve a formaçáo de professores para atuar frente a educação inclusiva, problematizou-se a necessidade de uma revisão sistemática em um periódico específico sobre educaçáo especial e realizar um levantamento bibliográfico do tema para contribuir para o arcabouço teórico de futuras produçóes almejadas nesta área de pesquisa.

Constata-se que o tema formação de professores nas publicaçóes da Revista Brasileira de Educação Especial aborda a análise da/na formação inicial de professores com enfoque ao curso de Pedagogia; a formação de professores como prática colaborativa para inclusão com ênfase na parceria entre diversos profissionais (especializados e da sala de aula regular) para prática pedagógica inclusiva; a análise de curso/ programa de formaçáo continuada com ênfase na modalidade à distância; revisóes e análises de produçóes científicas acerca da formação de professores com ênfase na contribuição de divulgação de pesquisa realizadas frente ao tema e; por fim, sobre a necessidade de formação pedagógica atrelada a carência de grupo ou área específica de atuação educacional.

Sublinha-se o estudo da prática colaborativa para efetivação da inclusão educacional, esse modo cria possibilidades de investigação entre formação e atuação pedagógica dos professores no ensino regular problematizando as intençóes até as práticas inclusivas como desafio imperante na sociedade contemporânea.

Esta pesquisa resultou na observação que o tema formaçáo de professores para inclusão apesar de ter assumido papel de relevância nas pesquisas, tem ocupado espaço menor como elemento central dos estudos. Portanto, há necessidade de ampliar investigaçóes de modo que possam contribuir na divulgaçáo de trabalhos já desenvolvidos na formação inicial e continuada, bem como, conduzir reformulaçóes/reestruturaçóes nos cursos e programas.

\section{Referências}

BARDIN, L. Análise de Conteúdo. Lisboa: Ediçôes 70, 2009.

BARDY, L. R. et al. Objetos de Aprendizagem como recurso pedagógico em contextos inclusivos: subsídios para a formação de professores a distância. In: Revista Brasileira de Educaçáo Especial [online]. 2013, vol. 19, n. 2, p. 273 - 288. ISSN 1413-6538. Disponível em: <http://www.scielo.br/pdf/rbee/v19n2/a10v19n2.pdf>. Acesso em: 29 dez. 2014.

BENITEZ, P.; DOMENICONI, C. Capacitação de agentes educacionais: proposta de desenvolvimento de estratégias inclusivas. In: Revista Brasileira de Educaçấo Especial [online]. 2014, vol. 20, n. 3, p. 371 - 386. ISSN 1413 - 6538. Disponível em: <http://www.scielo.br/pdf/rbee/v20n3/04.pdf>. Acesso em: 29 dez. 2014. 
BISOL, C. A.; VALENTINI, C. B. Objeto virtual de aprendizagem incluir: recurso para a formação de professores visando à inclusấo. In: Revista Brasileira de Educaçáo Especial [online]. 2014, vol. 20, n. 2, p. 223 - 234. ISSN 1413-6538. Disponível em: <http://www.scielo.br/pdf/rbee/v20n2/06.pdf>. Acesso em: 29 dez. 2014 .

BRASIL. Declaração de Salamanca e Princípios, Políticas e Práticas na Área das Necessidades Educativas Especiais. Brasília: MEC, 1994. Disponível em: <http://portal.mec.gov.br/seesp/arquivos/txt/salamanca.txt>. Acesso em: 15 fev. 2015.

BRASIL. Declaraçáo Mundial sobre educaçáo para todos e plano de açáo para satisfazer as necessidades básicas de aprendizagem. Brasília: UNICEF, 1990b. Disponível em: <http://unesdoc.unesco.org/images/0008/000862/086291 por.pdf>. Acesso em: 15 fev. 2015.

FARIA, J. G. Formação, profissionalização e valorização do professor surdo: reflexôes a partir do Decreto 5.626/2005. In: Revista Brasileira de Educaçáo Especial [online]. 2011, vol. 17, n. 1, p. 87 - 100. ISSN 1413-6538. Disponível em: <http://www.scielo.br/pdf/rbee/v17n1/v17n1a07.pdf>. Acesso em: 29 dez. 2014.

FIORINI, M. L. S.; MANZINI, E. J. Inclusão de alunos com deficiência na aula de educação física: identificando dificuldades, açôes e conteúdos para prover a formação do professor. In: Revista Brasileira de Educaçáo Especial [online]. 2014, vol. 20, n. 3, p. 387 - 404. ISSN 1413-6538. Disponível em: <http://www.scielo.br/ $\mathrm{pdf} / \mathrm{rbee} / \mathrm{v} 20 \mathrm{n} 3 / 05 . \mathrm{pdf}>$. Acesso em: 29 dez. 2014.

FONSECA-JANES, C. R. X.; OMOTE, S. Os cursos de Pedagogia da Universidade Estadual Paulista e a Educaçăo Inclusiva. In: Revista Brasileira de Educaçáo Especial [online]. 2013, vol. 19, n. 3, p. 325 - 342. ISSN 1413-6538. Disponível em: <http://www.scielo.br/pdf/rbee/v19n3/03.pdf>. Acesso em: 29 dez. 2014.

GLAT, R.; PLETSCH, M. D. O papel da Universidade no contexto da política de Educaçăo Inclusiva: reflexôes sobre a formação de recursos humanos e a produção de conhecimento. In: Revista de Educaçáo Especial, Santa Maria, v. 23, n. 38, p. 345 - 356, set./dez. 2010. Disponível em: <http://www.ufsm.br/revistaeducacaoespecial>. Acesso em: 15 fev. 2015.

GREGUOL, M.; GOBBI, E.; CARRARO, A. Formação de professores para a educação especial: uma discussão sobre os modelos brasileiro e italiano. In: Revista Brasileira de Educaçáo Especial [online]. 2013, vol. 19, n. 3, p. 307 - 324. ISSN 1413-6538. Disponível em: <http://www.scielo.br/pdf/rbee/v19n2/a10v19n2.pdf>. Acesso em: 29 dez. 2014.

INGLES, M. A. et al. Revisão sistemática acerca das políticas de educação inclusiva para a formação de professores. In: Revista Brasileira de Educaçáo Especial. [online]. 2014, vol. 20, n. 3, p. 461 - 478. ISSN 1413-6538. Disponível em: <http://www.scielo.br/pdf/rbee/v20n3/10.pdf>. Acesso em: 29 dez. 2014.

JESUS, D. M.; BARRETO, M. A. S. C.; GONCALVES, A. F. S. A formação do professor olhada no/pelo GT15 - educação especial da anped: desvelando pistas. In: Revista Brasileira de Educaçáo Especial [online]. 2011, vol. 17, n.spe1, p. 77 - 92. ISSN 1413-6538. Disponível em: <http://www.scielo.br/pdf/rbee/v17nspe1/07. pdf>. Acesso em: 29 dez. 2014.

MARQUEZINE, M. C.; TRAMONTINA, V. M. In: Revista Brasileira de Educaçāo Especial. In: Revista Brasileira de Educaçáo Especial [online]. 2006, vol. 12, n.1, p. 101 - 122. ISSN 1413-6538. Disponível em: <http://www.scielo.br/pdf/rbee/v12n1/31987.pdf>. Acesso em: 29 dez. 2014.

MICHELS, M. H. Paradoxos da formação de professores para a Educação Especial: o currículo como expressão da reiteração do modelo médico-psicológico. In: Revista Brasileira de Educaçáo Especial [online]. 2005, vol. 11, n. 2, p. 255 - 272. ISSN 1413-6538. Disponível em: <http://www.scielo.br/pdf/rbee/v11n2/v11n2a7.pdf>. Acesso em: 29 dez. 2014.

ORTH, M. A.; MANGAN, P. K. V.; SARMENTO, D. F. Formação continuada de professores em informática na Educação Especial: análise de dissertações e teses. In: Revista Brasileira de Educaçáo Especial [online]. 2011, vol. 17, n. 3, p. 497 - 516. ISSN 1413-6538. Disponível em: <http://www.scielo.br/pdf/rbee/v17n3/ v17n3a10.pdf>. Acesso em: 29 dez. 2014.

PETERSON, P. J. Inclusão nos Estados Unidos: filosofia, implementação e capacitação de professores. In: Revista Brasileira de Educaçáo Especial [online]. 2006, vol. 12, n. 1, p. 3 - 10. ISSN 1413-6538. Disponível em: <http://www.scielo.br/pdf/rbee/v12n1/31981.pdf>. Acesso em: 29 dez. 2014.

RAMALHO, J. V. A. et al. A carência de formaçáo sobre a superdotação nas licenciaturas da ufpel: um estudo de caso. In: Revista Brasileira de Educaçáo Especial [online]. 2014, vol. 20, n. 2, p. 235 - 248. ISSN 14136538. Disponível em: <http://www.scielo.br/pdf/rbee/v20n2/07.pdf>. Acesso em: 29 dez. 2014. 
RODRIGUES, L. M. B. C.; CAPELLINI, V. L. M. F. Educação a Distância e formação continuada do professor. In: Revista Brasileira de Educaçáo Especial. [online]. 2012, vol. 18, n. 4, p. 615 - 628. ISSN 1413-6538. Disponível em: <http://www.scielo.br/pdf/rbee/v18n4/a06v18n4.pdf>. Acesso em: 29 dez. 2014.

ROSIN-PINOLA, A. R.; DEL PRETTE, Z. A. P. Inclusão escolar, formação de professores e a assessoria baseada em habilidades sociais educativas. In: Revista Brasileira de Educaçáo Especial. [online]. 2014, vol. 20, n. 3, p. 341-356. ISSN 1413-6538. Disponível em: <http://www.scielo.br/pdf/rbee/v20n3/02.pdf>. Acesso em: 29 dez. 2014.

SAMPAIO, R.F.; MANCINI, M.C. Estudos de revisão sistemática: um guia para síntese criteriosa da evidência científica. In: Revista Brasileira de Fisioterapia, São Carlos, v. 11, n. 1, p. 83 - 89, jan./fev. 2007. Disponível em: <http://www.scielo.br/pdf/rbfis/v11n1/12.pdf>. Acesso em: 29 dez.2014.

SANCHÉZ, P. A. A educação Inclusiva: um meio de construir escolas para todos no século XXI. Inclusáo: Revista da Educação Especial. Brasília, v. 1, n. 1, p. 7 - 17, 2005.

SOARES, M.T.N. Programa Educaçáo Inclusiva Direito à Diversidade: Estudo de caso sobre a estratégia de multiplicação de políticas públicas. Dissertação de Mestrado, Programa de Pós-graduação em Educação, Universidade Federal da Paraíba, 2010.

TOLEDO, E. H. de; VITALIANO, C. R. Formação de professores por meio de pesquisa colaborativa com vistas à inclusão de alunos com deficiência intelectual. In: Revista Brasileira de Educaçáo Especial [online]. 2012, vol. 18, n. 2, p. 319 - 336. ISSN 1413-6538. Disponível em: <http://www.scielo.br/pdf/rbee/v18n2/ v18n2a10.pdf>. Acesso em: 29 dez. 2014.

VIEIRA, F. B. A.; MARTINS, L. A. R. Formação e criatividade: elementos implicados na construção de uma escola inclusiva. In: Revista Brasileira de Educaçáo Especial [online]. 2013, vol. 19, n. 2, p. 225 - 242. ISSN 1413-6538. Disponível em: <http://www.scielo.br/pdf/rbee/v19n2/a07v19n2.pdf>. Acesso em: 29 dez. 2014.

VITALIANO, C. R. Análise da necessidade de preparaçáo pedagógica de professores de cursos de licenciatura para inclusão de alunos com necessidades educacionais especiais. In: Revista Brasileira de Educaçáo Especial [online]. 2007, vol. 13, n. 3, p. 399 - 414. ISSN 1413-6538. Disponível em: < http://www.scielo.br/pdf/rbee/ v13n3/a07v13n3.pdf>. Acesso em: 29 dez. 2014.

VITALIANO, C. R (Org.). Formaçáo de professores para inclusão de alunos com necessidades educacionais especiais. Londrina: EDUEL, 2010.

\section{Correspondência}

Vanderley Flor da Rosa - Universidade Tecnológica Federal do Paraná, Campus Cornélio Procópio. Av. Alberto Carazzai, 1940 - Centro. CEP: 86300-000 - Cornelio Procópio, Paraná, Brasil.

E-mail: jacqueline_lidiane@hotmail.com - vanderley@utfpr.edu.br

Recebido em 09 de outubro de 2015

Aprovado em 16 de março de 2016 
